\title{
Cof a 1: Identification, Expression and Immunoreactivity of the First Coffee Allergen
}

\author{
Nikolay Manavski ${ }^{\mathrm{a}} \quad$ Ulrike Peters ${ }^{\mathrm{a}}$ Reinhold Brettschneider ${ }^{\mathrm{a}}$ \\ Marcus Oldenburg ${ }^{b}$ Xaver Baur ${ }^{b}$ Cordula Bittner ${ }^{b}$ \\ ${ }^{a}$ Biocenter Klein Flottbek and Botanical Garden, University of Hamburg, and ${ }^{b}$ Institute for Occupational Medicine \\ and Maritime Medicine, University Medical Center Hamburg-Eppendorf, Hamburg, Germany
}

\section{Key Words}

Cof a $1 \cdot$ Coffee allergy $\cdot$ Class III chitinase $\cdot$ Recombinant allergens $\cdot \mathrm{cDNA}$ phage display

\begin{abstract}
Background: Over the past years, dust of green coffee beans has become known to be a relevant cause for occupational type I allergies. Up to now, allergy diagnostics is based on native green coffee bean extract which exhibits insufficient specificity due to interfering substances as well as batch-tobatch variations. No coffee allergen has been described on the molecular level so far. The aim of this study was to identify the first allergen of green coffee. Methods: The allergenicity of native green coffee bean extracts was analyzed by means of ImmunoCAP in sera of 17 symptomatic coffee workers. A Coffea arabica pJuFo cDNA phage display library was constructed and screened for IgE binding to coffee proteins with 2 sera from allergic coffee workers. By sequence analysis, a new coffee allergen (Cof a 1) was identified, expressed in Escherichia coli, and evaluated by Western blots. The frequency of sensitization was investigated by ELISA screening. Results: The Cof a 1 cDNA encoded a 32-kDa $C$. arabica class III chitinase. Serum IgE antibodies to the recombinant allergen were found in 3 out of 17 symptomatic coffee
\end{abstract}

workers (18\%), whereas only 2 of them reacted to the commercial allergy test. Conclusions: A class III chitinase of $C$. arabica was identified to be the first known coffee allergen Cof a 1. It may have a relevant potential for the specific diagnosis of coffee sensitization.

Copyright $\odot 2012$ S. Karger AG, Basel

\section{Introduction}

By the middle of the 20th century, Figley and Rawling [1] noticed a high prevalence of asthma among workers of the coffee processing industry, which was caused by type I sensitization to castor beans from contaminated jute bags. In the 1950th and 1960th, allergic airway diseases in coffee workers were attributed to allergies to green coffee beans for the first time [2-5]. In the following, Lehrer et al. [6] showed by RAST inhibition tests that allergens from coffee beans and castor beans differ. Karr et al. [7] examined symptomatic coffee workers with skin prick and serological tests based on green coffee extracts and found exclusively positive results. Later on, type I al-

N.M. and U.P. contributed equally to this work.

\section{KARGER}

Fax +41613061234 E-Mail karger@karger.ch www.karger.com
(C) 2012 S. Karger AG, Basel

$1018-2438 / 12 / 1593-0235 \$ 38.00 / 0$

Accessible online at:

www.karger.com/iaa
Correspondence to: Dr. med. Cordula Bittner

Institute for Occupational Medicine and Maritime Medicine (ZfAM)

University Medical Center Hamburg-Eppendorf

Seewartenstrasse 10, DE-20459 Hamburg (Germany)

Tel. +49 40428894 468, E-Mail cordula.bittner@ bgv.hamburg.de 
Table 1. Demographic data, clinical symptoms and test results in coffee industry workers

\begin{tabular}{|c|c|c|c|c|c|c|c|}
\hline $\begin{array}{l}\text { Subject } \\
\text { No. }\end{array}$ & $\begin{array}{l}\text { Age } \\
\text { years }\end{array}$ & Sex & Work-related symptoms & $\begin{array}{l}\text { Total IgE } \\
\text { kU/l (CAP) }\end{array}$ & $\begin{array}{l}\text { Sensitization to } \\
\text { green coffee beans } \\
\text { CAP class (CAP) }\end{array}$ & $\begin{array}{l}\text { Sensitization } \\
\text { to rCof a } 1^{1} \\
\text { (ELISA) }\end{array}$ & $\begin{array}{l}\text { Sensitization } \\
\text { to rCof a } 1^{2} \\
\text { (ELISA) }\end{array}$ \\
\hline 1 & 44 & $\mathrm{~m}$ & rhinoconjunctivitis & 41 & 0 & - & - \\
\hline 2 & 33 & $\mathrm{~m}$ & conjunctivitis & 20 & 0 & - & - \\
\hline 3 & 28 & $\mathrm{~m}$ & rhinoconjunctivitis & 35 & 0 & - & - \\
\hline 4 & 32 & $\mathrm{~m}$ & rhinoconjunctivitis & 174 & 3 & $\mathrm{x}$ & $\mathrm{x}$ \\
\hline 5 & 43 & $\mathrm{~m}$ & rhinoconjunctivitis & 210 & 0 & - & - \\
\hline 6 & 34 & $\mathrm{~m}$ & rhinoconjunctivitis & 59 & 0 & - & - \\
\hline 7 & 34 & $\mathrm{~m}$ & rhinoconjunctivitis & 643 & 2 & $\mathrm{x}$ & $\mathrm{x}$ \\
\hline 8 & 42 & $\mathrm{~m}$ & rhinitis & 12 & 0 & - & - \\
\hline 9 & 48 & $\mathrm{~m}$ & conjunctivitis & 49 & 0 & - & - \\
\hline 10 & 60 & $\mathrm{~m}$ & rhinitis & 222 & 0 & $\mathrm{x}$ & $\mathrm{x}$ \\
\hline 11 & 28 & $\mathrm{~m}$ & rhinoconjunctivitis & 142 & 0 & - & - \\
\hline 12 & 32 & $\mathrm{~m}$ & rhinoconjunctivitis & 14 & 0 & - & - \\
\hline 13 & 41 & $\mathrm{~m}$ & rhinoconjunctivitis & 3 & 0 & - & - \\
\hline 14 & 41 & $\mathrm{~m}$ & conjunctivitis & 25 & 0 & - & - \\
\hline 15 & 56 & $\mathrm{~m}$ & rhinoconjunctivitis & 52 & 0 & - & - \\
\hline 16 & 41 & $\mathrm{~m}$ & conjunctivitis & 33 & 0 & - & - \\
\hline 17 & 48 & $\mathrm{~m}$ & conjunctivitis & 136 & 0 & - & - \\
\hline
\end{tabular}

lergies to green coffee beans were diagnosed by skin prick tests and coffee dust provocation [8-13]. Since then, an increasing number of work-related airway disorders have been reported in coffee workers. The prevalence of eye and/or airway symptoms in coffee workers is stated between 13 and $>50 \%[14,15]$. Therefore, a relevant number of affected people has to be assumed in terms of worldwide coffee processing of 7 million tons per year.

In spite of that, reliable diagnostic tools for coffee sensitization are not yet commercially available. Nowadays, the only allergy test commercially available is based on a mixture of green coffee bean extracts. These native extracts differ in antigen concentration and composition due to non-standardized allergen sources and preparation procedures. This might falsify the test results. Therefore, there is a need for improvement and standardization of diagnostic tools for allergy to green coffee dust, i.e. by means of highly specific and sensitive recombinant diagnostic tests.

In the following, we demonstrate the identification and molecular characterization of the first coffee allergen, namely Cof a 1 . We used the phage display technique, which was demonstrated to be a promising method for identifying allergens $[16,17]$.

\section{Materials and Methods}

\section{Investigated Sera}

To detect coffee allergens, sera were collected from 17 coffee industry workers employed by a haulage company $(n=9)$, in a coffee silo $(n=4)$ and by a decaffeinating company $(n=4)$ (all the companies are situated in Northern Germany), all complaining about work-related rhinitis and/or conjunctivitis during exposure to coffee dust (table 1). Specific IgE antibodies to green coffee beans (k70, Phadia, Freiburg, Germany) were detected in 2 sera (CAP classes 2 and 3). Elevated total IgE levels (>100 kU/l) occurred 6 times in the 17 sera. None of the employees reported symptoms after drinking coffee. All of the 17 workers had signed an informed consent form to participate in this study, and the authors received institutional review board approval for the study. The participants were all males, with an average age of 40 years (range 28-60). The control sera were from 8 subjects (4 females and 4 males, with an average age of 37 years) not occupationally exposed to coffee dust. In none of the controls an obstructive airway disease has ever been diagnosed; furthermore, none of them had a known sensitization to occupational allergens so far. All sera have been stored at $-20^{\circ} \mathrm{C}$ until analysis was performed.

\section{Phadia CAP System}

To determine the levels of total and allergen-specific IgE antibodies in 17 sera from subjects with work-related rhinitis and/or conjunctivitis after coffee dust exposure, a CAP assay was performed according to the manufacturer's instructions of the Im- 
munoCAP system (Phadia). For detection of allergen-specific IgE antibodies, CAP analysis was carried out with commercially available sponges coupled with a protein extract from green coffee beans (k70, Phadia). The results were expressed as CAP scores of classes $0-6$. The cutoff value for significant positivity was 0.35 $\mathrm{kU} / \mathrm{l}$ (CAP class 1 ). Total IgE was detected by ImmunoCAP (Phad$\mathrm{ia})$, and the results were expressed as concentration of $\operatorname{IgE}(\mathrm{kU} / \mathrm{l})$.

\section{Construction of the cDNA Library}

A cDNA $\lambda$ TriplEx 2 library from immature green coffee cherries (Coffea arabica) was constructed using the SMART cDNA library construction kit (Clontech, St-Germain-en-Laye, France) and the Gigapack gold packaging extract (Stratagene, Heidelberg, Germany), according to the respective manufacturer's instructions. Briefly, $1 \mu \mathrm{g}$ of total RNA was used as starting material to generate double-stranded cDNA according to the PCR-based method. After in vivo conversion of the $\lambda$ TriplEx 2 library into a pTriplEx2 plasmid population, recombinant plasmids were isolated as described previously [18]. One hundred micrograms of plasmid DNA were digested with EcoRI/XhoI, and resulting inserts were ligated into the EcoRI and XhoI sites of pJufo II (kindly supplied by Professor R. Crameri, Department of Molecular Allergology, Swiss Institute of Allergy and Asthma Research, Davos, Switzerland).

\section{Biopanning}

For identification of IgE-binding proteins presented on the phage surface, the phage display cDNA library was screened by a biopanning approach as described recently [17]. The procedure was performed with 2 sera of the 17 subjects with sensitization to green coffee beans detected by ImmunoCAP (k70, Phadia).

\section{Cloning of C. arabica Cof a 1}

The cDNA insert of the affinity-selected clone coding for Cof a 1 was sequenced using the ABI Prism Big Dye reaction kit (Applied Biosystems, Darmstadt, Germany) and an ABI Prism sequencer. Two oligonucleotides (forward: ATATATACTAGT/GATGACGACGACAAGGCTGGAATTGTCCGGTACTGGG, reverse: ATATATCTCGAGCATGATGCCTCCATAAACAGGAGAC) containing SpeI/enterokinase and XhoI sites, respectively, were designed to flank the majority of the GH18_hevamine_XipI_class_III domain of mature Cof a 1 excluding the endoplasmic reticulum signal sequence (amino acids 1-27), and the last 22 residues of the mature protein consisted of 263 amino acids. This domain family consists of xylanase inhibitor Xip-I and class III plant chitinases, which have a glycosyl hydrolase family 18 (GH18) domain. Class III plant chitinases include class III endochitinases that hydrolyze the linear polysaccharide chains of chitin and peptidoglycan and class III chitinases that hydrolyze $\beta_{1-4}$-glycosidic bonds linking 2 -acetoamido-2-deoxy- $\beta$-D-glucopyranose units in chitin. The cDNA needed for the generation of the C. arabica cDNA library was used in PCR amplification as template. The PCR product was digested with SpeI and XhoI and inserted into Escherichia coli protein expression vector pET-41 b(+) (Novagen, Darmstadt, Germany). After confirming the proper sequence of the clone, it was transformed into E. coli BL21 (DE3) cells (Novagen).

\section{Sequence Analysis}

Sequence data were analyzed using the programs included in DNASTAR 4.05 software package. Protein domains were identi- fied using the ScanProsite tool of the ExPASy Proteomics Server (http://www.expasy.ch/tools/scanprosite) [18]. The presence of the targeting signal was determined using TargetP and SignalP 3.0 (http://www.cbs.dtu.dk/services/SignalP) [19, 20]. Alignments were calculated with ClustalW2 (http://www.ebi.ac.uk/ Tools/clustalw2/index.html) and visualized by GeneDoc 2.6.002 (http://www.psc.edu/biomed/genedoc) [21, 22].

Expression and Affinity Purification of Recombinant Cof a 1

To generate a recombinant glutathione $S$-transferase (GST)Cof a 1-His fusion protein, the GH18_hevamine_XipI_class_III domain of mature Cof a 1 was cloned into the high level expression vector $\mathrm{pET}-41 \mathrm{~b}(+)$, as described above. The resulting $\mathrm{pET}-41$ $\mathrm{b}(+) /$ Cof a 1 construct was introduced into E. coli BL21 (DE3) cells. Cultures were grown at $37^{\circ} \mathrm{C}$ in lysogeny broth medium with kanamycin to an $\mathrm{OD}_{550 \mathrm{~nm}}$ of 0.6.

For native GST affinity purification, the culture was transferred onto ice for $30 \mathrm{~min}$ and then grown further for $4 \mathrm{~h}$ at $22^{\circ} \mathrm{C}$ in the presence of isopropyl- $\beta$-D-thiogalactopyranoside (IPTG) to $1 \mathrm{mM}$. Precipitated cells were lysed by addition of lysozyme to a final concentration of $0.3 \mathrm{mg} / \mathrm{ml}$ and subsequent sonification in ice-cold lysis buffer $\left(4.3 \mathrm{mM} \mathrm{Na}_{2} \mathrm{HPO}_{4}, 1.47 \mathrm{mM} \mathrm{KH}_{2} \mathrm{PO}_{4}, 137 \mathrm{mM}\right.$ $\mathrm{NaCl}, 2.7 \mathrm{mM} \mathrm{KCl}, \mathrm{pH} 7.3)$. The post-centrifugation supernatant was filtered through a $0.45-\mu \mathrm{m}$ syringe end filter and incubated with GST Bind Resin (Novagen) at $4^{\circ} \mathrm{C}$ for $1 \mathrm{~h}$. After three washes with lysis buffer, recombinant protein was eluted with elution buffer (50 mM Tris- $\mathrm{HCl}, \mathrm{pH}$ 8.0, $10 \mathrm{~mm}$ reduced glutathione).

For protein purification under denaturing conditions, the $E$. coli culture was supplemented with IPTG to a final concentration of $1 \mathrm{~mm}$ and incubated for $4 \mathrm{~h}$ at $37^{\circ} \mathrm{C}$. Harvested cells were ruptured by several freeze-thaw cycles and subsequent sonification in lysis buffer ( $8 \mathrm{M}$ urea, $100 \mathrm{mM} \mathrm{Na}{ }_{2} \mathrm{PO}_{4}, 10 \mathrm{mM}$ Tris- $\mathrm{HCl}, \mathrm{pH}$ 8.0). The supernatant was supplemented with imidazole at a final concentration of $10 \mathrm{mM}$ and incubated with Ni-NTA resin (Qiagen, Hilden, Germany) at room temperature for $1 \mathrm{~h}$. After washing with lysis buffer containing $20 \mathrm{~mm}$ imidazole, recombinant protein was eluted with the same buffer supplemented with 500 mM imidazole.

Protein concentration was determined by Bradford assay using bovine serum albumin as standard. Purity of recovered recombinant proteins was verified by SDS-PAGE.

\section{Immunoblot Analysis}

Bacterial protein extracts and purified recombinant proteins were separated by SDS-PAGE and transferred onto ECL membranes (GE Healthcare, Freiburg, Germany). Protein gel blots were performed with Penta-His antibody (Qiagen) at a dilution of $1 / 5,000$. Goat anti-mouse antibody conjugated to horseradish peroxidase (Pierce, Bonn, Germany) was used as secondary antibody at a dilution of 1/2,000. SuperSignal West Dura Extended Duration Substrate (Pierce) was utilized for antigen detection. Blots were exposed to X-ray film.

\section{ELISA}

Determination of the IgE-binding capacity of purified recombinant proteins was performed by an allergen-specific ELISA, as described recently [17]. The mean OD value $\left(\mathrm{A}_{405}\right)$ plus $3 \mathrm{SDs}$ of control sera from 8 unexposed and healthy subjects for the respective antigen was chosen as the cutoff point. Expression for sensitivity was a repetition of a positive test result. 
Fig. 1. Sequence alignment of Cof a 1 cDNA clone and its homologue NCBI express sequence tag GR983307. Lowercase letters depict the DNA sequence, whereas capital letters represent the deduced amino acid sequence. Identical regions are highlighted in grey. Underlined regions mark the binding sites of primers used in the RT-PCR. The position of the reverse primer was chosen to cover almost entirely the homologous region found between Cof a 1 and hevamine (see fig. 2). The predicted signal peptide is double underlined.

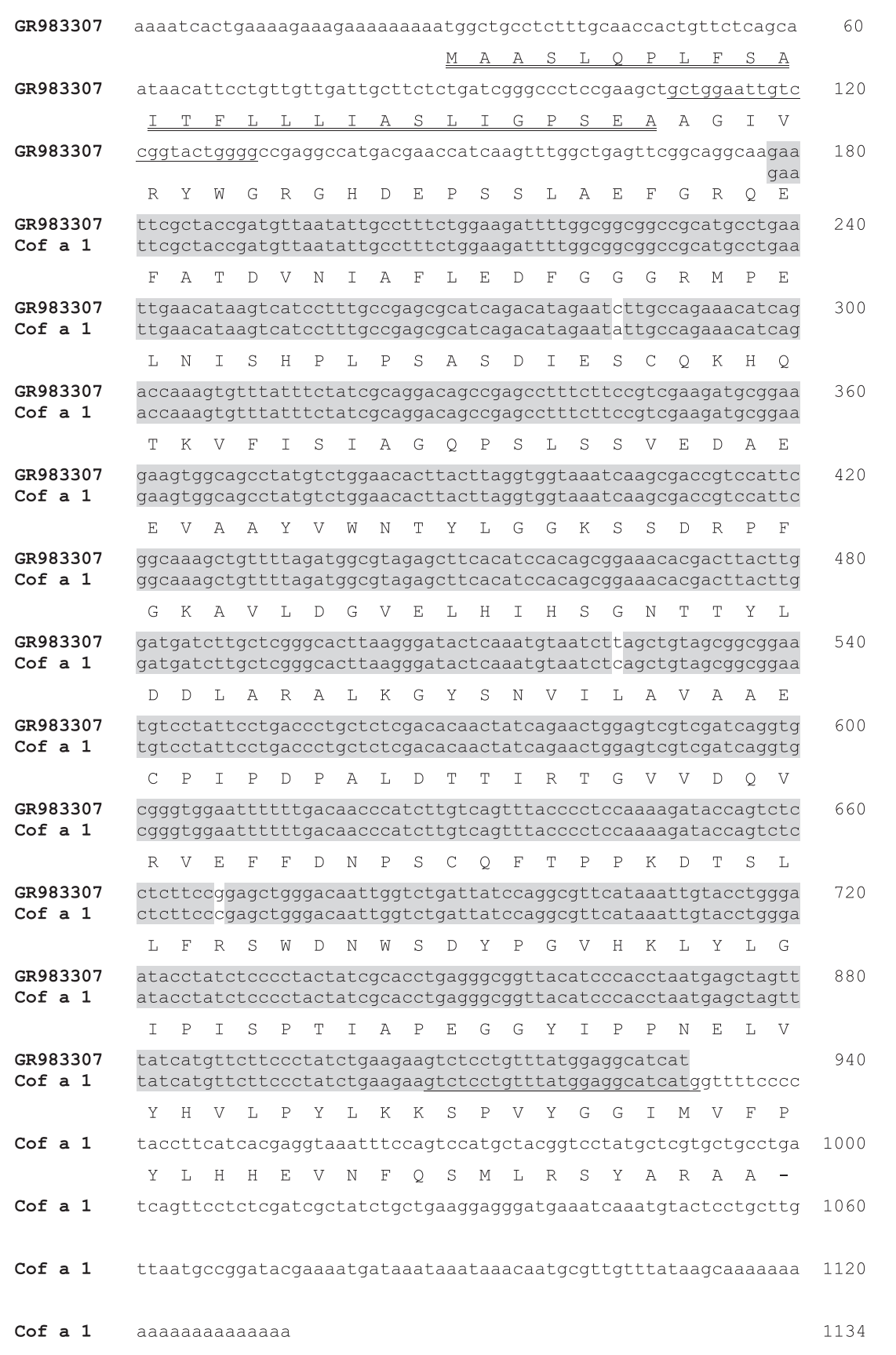

\section{Results}

\section{Identification of the cDNA Clone of Cof a 1}

The C. arabica phage display cDNA library was screened with 2 sera from coffee industry workers with symptoms of rhinoconjunctivitis and positive ImmunoCAP to green coffee beans. A total of 62 IgE-binding phages were obtained after three rounds of affinity selection. To identify the cDNAs encoding IgE-reactive peptides, phagemids were extracted from affinity-selected phages, and subsequent insert cDNA sequencing was carried out. A BLAST search in the National Center for Biotechnology Information (NCBI) expressed sequence tag database performed with a 857-bp cDNA insert, which 


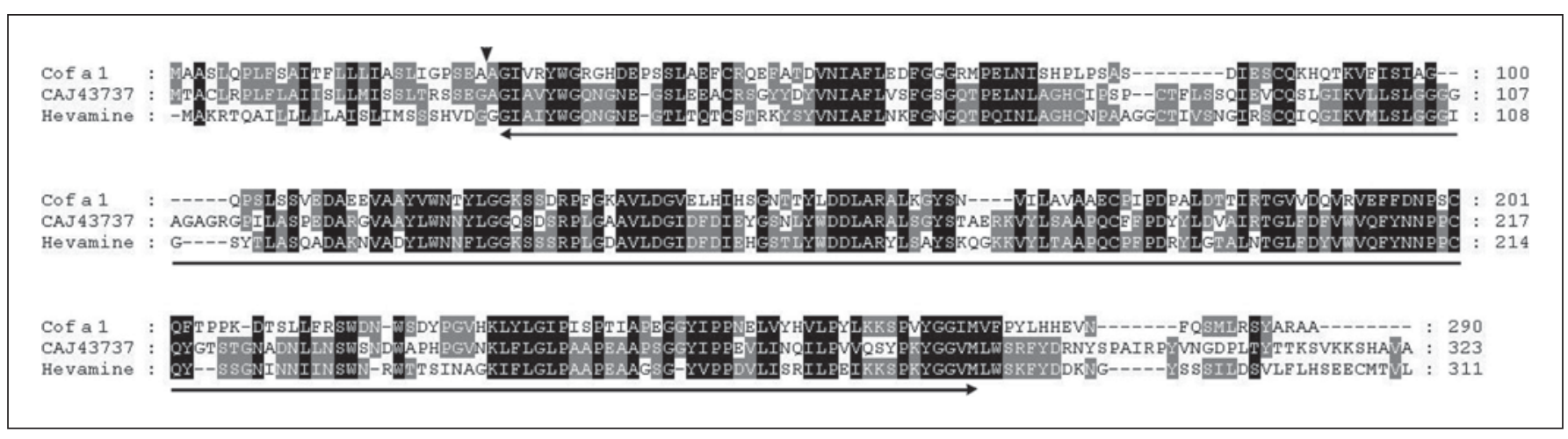

Fig. 2. Alignment of the amino acid sequences of Cof a $1, H$. brasiliensis hevamine (Hev b 14) and a C. arabica class III chitinase (CAJ43737) identified by BLAST search. The cleavage site of the predicted signal peptide is indicated by an arrowhead. The sequence region of Cof a 1 used for production of recombinant protein and subsequent immunological investigation is indicated by a double-headed arrow.

we named Cof a 1 , provided a nearly $100 \%$ sequence similarity over a region of $653 \mathrm{bp}$ to a C. arabica cDNA clone (GR983307) coding for an acidic endochitinase (fig. 1). Based on the sequence alignment of both clones, an open reading frame of $873 \mathrm{bp}$ corresponding to a protein of 290 amino acids with a calculated molecular mass of 31,820 $\mathrm{Da}$ was deduced. A signal peptide with a cleavage site between amino acids 27 and 28 was predicted by SignalP 3.0 and TargetP servers with high probability. Comparison with entries in the NCBI protein data base revealed $47 \%$ amino acid identity with a C. arabica class III chitinase (CAJ43737) (fig. 2). Furthermore, a conserved domain family (GH18_hevamine_XipI_class_III) including xylanase inhibitor Xip-I and class III plant chitinases such as concavalin B and hevamine, as well as the GH18 domain, was found using the ScanProsite tool of the ExPASy Proteomics Server. Since hevamine, a chitinase of the rubber plant Hevea brasiliensis, has been described as a major latex allergen, the sequence region of Cof a 1, which nearly covers the entire GH18_hevamine_XipI_class_III domain and shows relatively high amino acid similarity to hevamine (amino acids 28-268; fig. 2), was considered for further immunological investigation. The sequence has been submitted to the GenBank data library (accession No. HM 051339.1).

\section{Expression and Purification of Recombinant Cof a 1}

The coding region of the cDNA insert covering the majority of the GH18_hevamine_XipI_class_III domains (amino acids 28-268) was cloned into pET-41b(+) vector and expressed in E. coli strain BL 21 (DE3) as described in the Methods section. A high amount of the
GST-Cof a 1-His fusion protein could be expressed in soluble form and purified using GST affinity chromatography under non-denaturing conditions. GST-Cof a 1-His was additionally purified by Ni-NTA affinity chromatography under denaturing conditions. Examination of recovered proteins by SDS-PAGE and subsequent staining with Coomassie brillant blue revealed that GST-Cof a 1-His was strongly enriched as a band of the expected size of $55 \mathrm{kDa}$ (fig. 3a). Purified proteins were verified by immunodetection using anti-His antibody (fig. 3b).

\section{Immunoreactivity of Recombinant Cof a 1}

In this study, 17 sera from coffee industry workers with symptoms of rhinitis and/or conjunctivitis were used. In a preliminary CAP analysis, 6/17 (35\%) sera showed increased levels of total IgE. Sensitization to green coffee beans was found in 2/17 (12\%) sera using commercial CAP analysis (table 1).

To determine specific IgE reactivity to recombinant Cof a 1 (rCof a 1), the sera were screened by ELISA. IgE antibodies binding to rCof a 1 and purified under denaturing conditions were found in 3 out of 17 (18\%) sera, whereas the 2 sera reacting to ImmunoCAP native green coffee beans reacted to our recombinant allergen as well. When using rCof a 1 , obtained under native conditions, Cof a 1-specific IgEs were identified in the same 3 sera. In addition, significant amounts of Cof a 1-binding IgEs were measured in pooled sera from patients with latex allergy, indicating cross-reactivity to latex chitinases, presumably to Hev b 14. To rule out that the GST tag (22 $\mathrm{kDa}$ ), which was fused with rCof a 1, has IgE-binding capacity by itself, the sera were screened with purified re- 


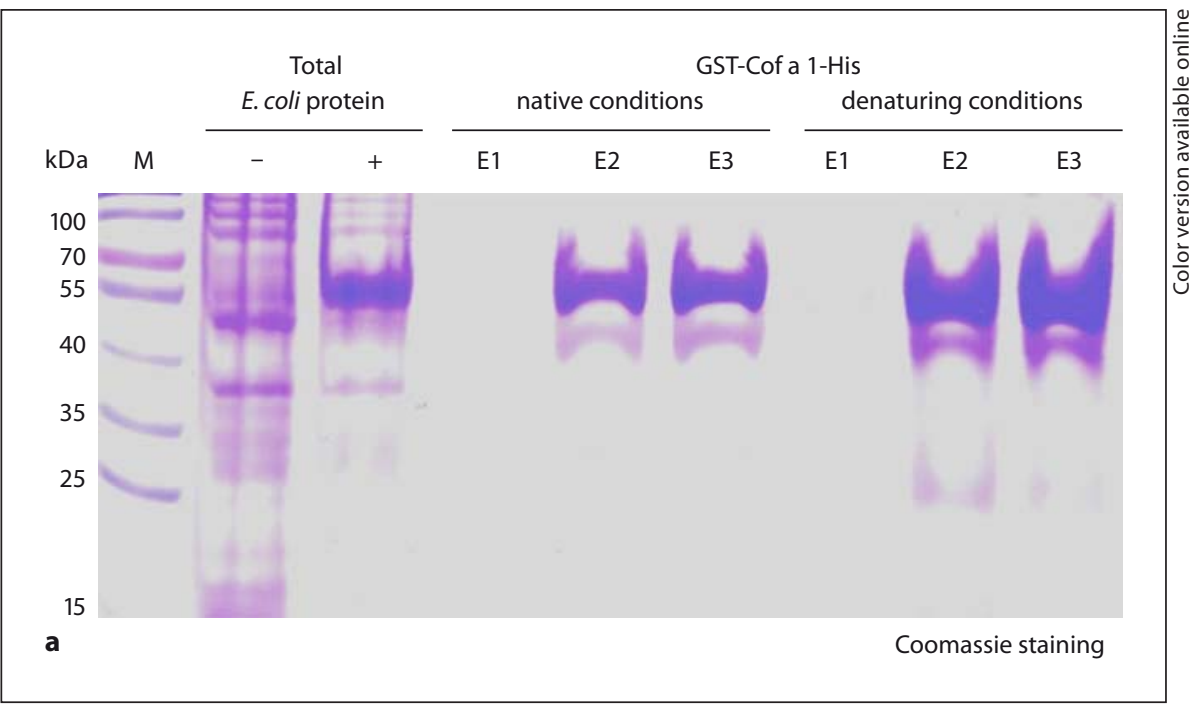

Fig. 3. Purification and immunodetection of rCof a 1 (GST-Cof a 1-His). a Purification of $\mathrm{rCof}$ a 1. Proteins recovered by GST and His affinity chromatography were separated by SDS-PAGE and stained with Coomassie brilliant blue. Total E. coli protein fractions before and after IPTG supplement are indicated by - and + , respectively. E1-E3 = Protein elution fractions; $\mathrm{M}=$ molecular weight marker. $\mathbf{b}$ Immunodetection of $E$. coli-expressed rCof a 1 using a Penta-His antibody. Immunoblot of total E. coli protein after IPTG induction $(+)$ and purified rCof a 1 obtained under native and denaturing (denat.) conditions. Immunodetection = Immunodetection with anti-His antibody; $\mathrm{M}=$ molecular weight marker.

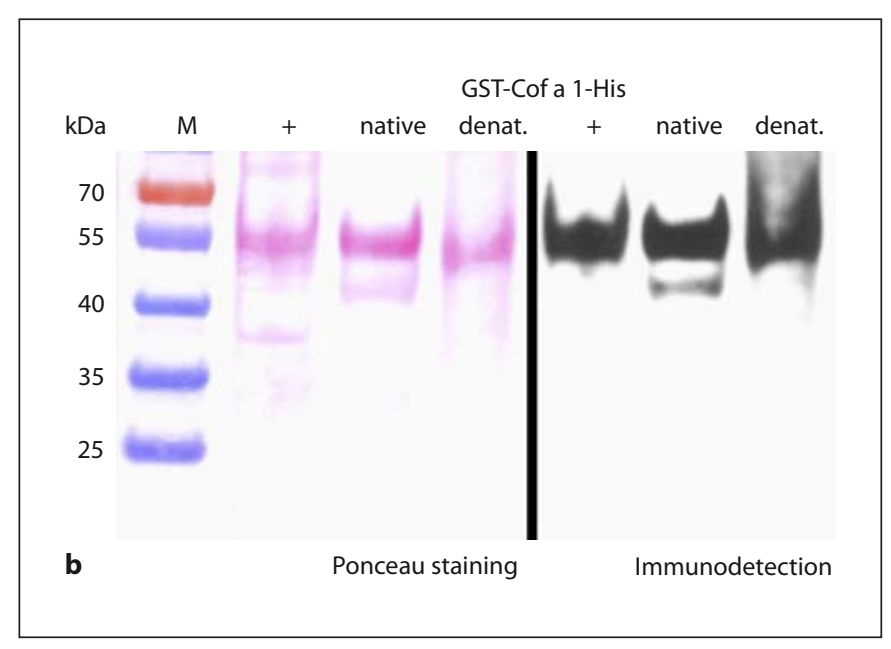

combinant GST. None of the 17 sera reacted with GST. An overview is shown in table 1.

All 8 control sera gave negative results to purified $\mathrm{rCof}$ al proteins (native and denatured; data not shown).

The name Cof a 1 for the allergen has been assigned by the World Health Organization/International Union of Immunological Societies Allergen Nomenclature SubCommittee after submitting the present data.

\section{Discussion}

An increased number of airway disorders has been reported in workers exposed to the dust of green coffee beans. Among others, allergic reactions to green coffee beans have been considered to be the cause [23-25]. Up to now, no single coffee allergen could be identified and characterized on the molecular level. The only test for serological antibody diagnostics currently commercially available is based on a mixture of natural allergen extracts from the species C. arabica, C. canephora and C. liberica. (ImmunoCAP to green coffee beans by phadia). These error-prone diagnostic tools often exhibit a pronounced lack of specificity and sensitivity due to varying allergen sources, preparation methods and possible contaminations, and might therefore lead to false-negative or falsepositive results. Recently, by use of commercial tests for green coffee beans, we detected specific IgE antibodies in just a small number of coffee workers with work-related allergic complaints during coffee dust exposure [26].

Furthermore, natural extracts from green coffee are useless and hazardous for skin test application and/or in- 
halative provocation because of vasodilating ingredients like caffeine and histamine, possibly leading to false-positive results up to anaphylactic reactions $[27,28]$. Therefore, notably, previous surveys based on skin and/or provocation test results with native coffee extract have to be interpreted with caution. Today, coffee extracts for skin prick tests and/or provocation tests are still not commercially available.

Problems associated with natural extracts used for allergy diagnosis might be overcome with the production and subsequent use of recombinant allergens as an alternative diagnostic approach $[29,30]$. The benefit of recombinant allergens is the possibility to produce a perfectly standardized diagnostic tool. Furthermore, individual sensitization patterns lead to improved diagnostic and therapeutic options, and allergic mechanisms and crossreactivities may be discovered [31]. Moreover, impurities and substances of the coffee itself, which may falsify the test results, can be eliminated.

To identify coffee allergens leading to rhinoconjunctivitis among coffee industry workers, we have constructed a cDNA library from green $C$. arabica cherries. In order to cover a broad range of different mRNAs, we harvested the coffee cherries at several stages of maturity. To identify cDNAs coding for potential allergens, the cDNA library was screened with sera from 2 subjects with rhinoconjunctivitis by means of the phage display technique. One clone of $857 \mathrm{bp}$ containing an incomplete open reading frame was considered for further investigations. Both DNA and protein homology searches identified the phage clone-derived allergen as a class III acidic endochitinase, which we named Cof a 1 (the name has been assigned by the World Health Organization/International Union of Immunological Societies Allergen Nomenclature SubCommittee after submitting the present data). A conserved GH18_hevamine_XipI_class_III domain, characteristic of this class of chitinases, was also found. Chitinases are enzymes that catalyze the hydrolysis of the $\beta-1,4-\mathrm{N}$-acetyl-D-glucosamine linkages in chitin. Since fungal pathogens contain chitin as a structural constituent, plant chitinases are thought to be an important part of the biochemical defense against pathogens and are therefore counted among pathogenesis-related (PR) proteins $[32,33]$. Since many PR proteins have already been described as allergens, it is conceivable that these very common features might abet a protein to become an allergen [34]. By conducting an ELISA with pooled sera of health care workers sensitized to the latex chitinase hevamine, a major latex allergen [35], we were able to show that cross-reactivities occur between chitinases of differ- ent plants. In the future, it might be interesting to look into latex intolerance in allergic coffee workers.

Typically for PR proteins is a relatively small molecular mass, proteolytic resistance and protein stability at low $\mathrm{pH}$ [33]. Accordingly, the detected 31,800-Da large recombinant allergen is a relatively small coffee allergen. Lehrer et al. $[6,36]$ stated that small coffee allergens are heat stable. Therefore, it may be assumed that this allergen is not destroyed by the roasting process of green coffee beans and the digesting procedure, respectively.

Tests with the commercially available ImmunoCAP of green coffee beans in a collective of 17 coffee workers with work-related allergic symptoms of rhinitis and/or conjunctivitis exhibited the presence of IgE antibodies in only 2 cases. As the test is based on native green coffee extracts, beside an irritative mechanism of the clinical symptoms, a limited reliable test method leading to low test results has to be considered. Nonetheless, testing with our recombinant allergen lead to 3 positive test results (in addition to the 2 CAP-positive sera, 1 CAP-negative serum showed IgE binding). This fact verifies an allergic potential of green coffee beans - and a deficient sensitivity of the only commercial allergy test to green coffee beans. Therefore, an improvement in diagnostic (and maybe therapeutic) tools is necessary. More sensitive diagnostic tests capturing the majority of affected men have to be developed. An exploration of further single coffee allergens may be of benefit for hundreds of thousands of people working in the coffee industry.

\section{Acknowledgements}

We thank Professor R. Crameri for supplying pJuFo II and Frauke Koops for her skilful technical assistance. We also thank Sönke Jäger for proofreading the manuscript.

References

Int Arch Allergy Immunol 2012;159:235-242
1 Figley KD, Rawling FFA: Castor bean: an industrial hazard as a contaminant of green coffee dust and used burlap bags. J Allergy 1950;21:545-553.

$\checkmark 2$ Bruun E: Allergy to coffee. Acta Allergol 1957;11:150-154.

-3 Kaye M, Freedman SO: Allergy to raw coffee - an occupational disease. Can Med Assoc J 1961;84:469-471.

4 Freedman SO, Krupey J, Sehon AH: Chlorogenic acid: an allergen in green coffee bean. Nature 1961;192:241-243.

5 Layton LL, Greene FC, Panzani R, Corse JW: Allergy to green coffee. J Allergy 1965;36: 84-91. 
6 Lehrer SB, Karr RM, Salvaggio JE: Analysis of green coffee bean and castor bean allergens using RAST inhibition. Clin Allergy 1981;11:357-366.

7 Karr RM, Lehrer SB, Butcher RT, Salvaggio JE: Coffee worker's asthma: a clinical appraisal using the radioallergosorbent test. J Allergy Clin Immununol 1978;62:143-148.

8 Wallenstein G, Schöneich R: Arbeitsbedingte allergische Atemwegserkrankungen durch Kaffeestaub. Dt Gesundheitswesen 1983;38:433-435.

$\checkmark 9$ De Zotti R, Patussi V, Fiorito A, Larese F: Sensitization to green coffee bean and castor bean allergens among dock workers. Int Arch Occup Environ Health 1988;61:7-12.

10 Müsken H, Bergmann K-C, Wahl R, Hittmann-Cammann F: Allergisches Asthma durch Rohkaffeestaub. Allergologie 1992;15: 25-28.

-11 Romano C, Sulotto R, Piolatto G, Ciacco C, Capellaro E, Falagiani P, et al: Factors related to the development of sensitization to green coffee and castor bean allergens among coffee workers. Clin Exp Allergy 1995;25:643650 .

12 Treudler R, Tebbe B, Orfanos CE: Kaffeeallergie. Allergo J 1996;5:30.

13 Lemière C, Malo JL, McCants M, Lehrer S: Occupational asthma by roasted coffee: immunologic evidence that roasted coffee contains the same antigens as green coffee, but in a lower concentration. J Allergy Clin Immunol 1996;98:464-466.

14 Thomas KE, Trigg CJ, Baxter PJ, Topping M, Lacey J, Crook B, et al: Factors relating to the development of respiratory symptoms in coffee process workers. Brit J Ind Med 1991; 48:314-322.

-15 Osterman K, Zetterström O, Johannson SGO: Coffee worker's allergy. Allergy 1982; $37: 313-322$.
16 Crameri R, Achatz G, Weichel M, Rhyner C: Direct selection of cDNAs by phage display. Methods Mol Biol 2002;185:461-469.

- 17 Bittner C, Grassau B, Frenzel K, Baur X: Identification of wheat gliadins as an allergen family related to baker's asthma. J Allergy Clin Immunol 2008;121:744-749.

$\checkmark 18$ Birnboim HC, Doly J: A rapid alkaline extraction procedure for screening recombinant plasmid DNA. Nucleic Acids Res 1979; 7:1513-1523.

-19 Emanuelsson O, Nielsen H, Brunak S, von Heijne G: Predicting subcellular localization of proteins based on their N-terminal amino acid sequence. J Mol Biol 2000;300:10051016.

20 Bendtsen JD, Nielsen $H$, von Heijne G, Brunak S: Improved prediction of signal peptides: SignalP 3.0. J Mol Biol 2004;340: 783-795.

21 Larkin MA, Blackshields G, Brown NP, Chenna R, McGettigan PA, McWilliam H, et al: Clustal W and Clustal X version 2.0. Bioinformatics 2007;23:2947-2948.

22 Nicholas KB, Nicholas HBJ: GeneDoc: a tool for editing and annotating multiple sequence alignments. 1997. http://www.psc.edu/ biomed/genedoc.

23 Lehrer SB, Karr RM, Savaggio JE: Extraction and analysis of coffee bean allergens. Clin Allergy 1978;8:217-226.

24 Zuskin E, Valic F, Kanceljak B: Immunolog ical and respiratory changes in coffee workers. Thorax 1981;36:9-13.

$>25$ Larese F, Fiorito A, Casasola F, Molinari S, Peresson M, Barbina P, Negro C: Sensitization to green coffee beans and work-related allergic symptoms in coffee workers. Am J Ind Med 1998;34:623-627.

26 Oldenburg M, Bittner C, Baur X: Health risks due to coffee dust. Chest 2009;136:536544 .
27 Zuskin E, Duncan PG, Douglas JS: Pharmacological characterization of extracts of coffee dusts. Br J Ind Med 1983;40:193-198.

28 Zuskin E, Kanceljak B, Witek TJ Jr, Schachter $\mathrm{EN}$ : Acute ventilator response to green coffee dust extract. Ann Allergy 1991;66:219-224.

-29 Egger M, Hauser M, Himly M, Wopfner N, Wallner M, Ferreira F: Development of recombinant allergens for diagnosis and therapy. Front Biosci (Elite Ed) 2009;1:77-90.

30 Chapman MD, Ferreira F, Villalba M, Cromwell O, Bryan D, Becker WM, et al: The European Union CREATE project: a model for international standardization of allergy diagnostics and vaccines. J Allergy Clin Immunol 2008;122:882-889.

31 Valenta R, Twardosz A, Vrtala S, Kraft D: Large scale production and quality criteria of recombinant allergens. Arb Paul Ehrlich Inst Bundesamt Sera Impfstoffe Frankf a.M.

1999;93:211-224.
32 Collinge DB, Kragh KM, Mikkelsen JD, Nielsen KK, Rasmussen U, Vad K: Plant chitinases. Plant J 1993;3:31-40.

33 Hoffmann-Sommergruber K: Plant allergens and pathogenesis-related proteins: what do they have in common? Int Arch Allergy Immunol 2000;122:155-166.

34 Hoffmann-Sommergruber K: Pathogenesisrelated $(\mathrm{PR})$ proteins identified as allergens. Biochem Soc Trans 2002;30:930-935.

35 Posch A, Chen Z, Wheeler C, Dunn MJ, Raulf-Heimsoth M, Baur X: Characterization and identification of latex allergens by two-dimensional electrophoresis and protein microsequencing. J Allergy Clin Immunol 1997;99:385-395.

-36 Lehrer SB, Taylor J, Salvaggio JE: Castor bean allergens: evidence for distinct heat-labile and stabile entities. Int Arch Allergy Appl Immunol 1981;65:69-75. 